\section{A study on the determination of sex using lip print patterns among indigenes of Akwa Ibom State, Nigeria}

\author{
${ }^{1}$ Department of Human Anatomy, University of Calabar, Calabar, Nigeria \\ ${ }^{2}$ University of Calabar, Calabar, Nigeria \\ ${ }^{3}$ Kampala International University Western Campus, Uganda
}

Obosi $\mathrm{NJ}^{1 *}$, Akpantah $\mathrm{AO}^{2}$, Archibong VB³ and Duru GO²

\section{Abstract}

The lip print pattern is the characteristic pattern of the wrinkles and grooves present on the labial mucosa. This study evaluated the determination of sex among indigenes of Akwa lbom State, Nigeria using lip print patterns. 100 subjects (50 males and 50 females), aged 18-25 years participated in the study. With written consent, lip prints were collected from the subjects. Samples were analyzed using Suzuki and Tsuchihashi classification of lip prints. The lip samples were analyzed as a whole and then divided into six portions Right Upper Portions, Middle Upper Portion, Left Upper Portion, Right Lower Portion, Middle Lower Portion and Left Lower Portion and analyzed differently. Data were analyzed using the Chi-square test and T - test analysis. The result shows that the most prevalent lip print in males considering the lip as a whole is Type I (29\%) while that of the females is Type I' $(32 \%)$. In six portions, there was a significant difference $(p<0.05)$ between the lip print patterns in male and female subjects in the Right Upper Portion (25.960), Left Upper Portion (15.455) and Middle Left Portion (19.948) suggesting that these portions can be effectively used for sex determination among these indigenes. There was no significant difference $(p>0.05)$ between the thickness of lip in males and in females but, the lower lip was significantly thicker $(p<0.01)$ than the upper lip in both gender. Results also showed that the length of lips in males was significantly longer $(p<0.01)$ than that of females. This study, therefore, concludes that determination of sex among indigenes of Akwa lbom State using lip length and lip print patterns in specific portions of Right Upper Portion, Left Upper Portion and Middle Left Portion can be effectively done.

\section{Introduction}

Numerous elevations and depressions that form a characteristic pattern on the external surface of lips are referred to as lip prints [1]. They are the normal lines and fissures in the form of wrinkles and grooves present in the zone of transition of the human lip between the inner labial mucosa and outer skin [2]. Lip prints cannot be altered throughout a person's life span and they are distinctive to a person except in monozygotic twins [1].

The establishment of a person's individuality is important for legal as well as anthropometrical purposes [3]. The most common techniques for identification has been odontology, DNA profiling, fingerprint, etc. However, in some crime scenes, the above means of identification may not be available and cheiloscopy can be employed. Obtaining lip prints after death has to be done within a day in order to avoid errors in information obtained due to post-mortem changes of the lip [4]. include (Figure 1): grooves).

\section{More Information}

*Address for Correspondence: Obosi NJ Department of Human Anatomy, University of Calabar, Calabar. 540242-Nigeria, Email: nsisongobosi@yahoo.com

Submitted: December 31, 2021

Approved: January 27, 2022

Published: January 28, 2022

How to cite this article: Obosi NJ, Akpantah AO, Archibong VB, Duru GO. A study on the determination of sex using lip print patterns among indigenes of Akwa Ibom State, Nigeria. J Forensic Sci Res. 2022; 6: 017-023.

DOI: 10.29328/journal.jfsr.1001032

ORCiD: orcid.org/0000-0001-6952-920X

Copyright License: ( 2022 Obosi NJ, et al. This is an open access article distributed under the Creative Commons Attribution License, which permits unrestricted use, distribution, and reproduction in any medium, provided the original work is properly cited.

Keywords: Lip length; Subjects; Lip samples

(W) Check for updates

(3) OPEn ACCESS

Lip print patterns can be classified [5,6] into six types depending on the shape and course of the grooves. These

Type I: Vertical, comprising of complete longitudinal fissures (complete straight grooves).

Type I': Incomplete longitudinal fissures (partial straight

Type II: Branching $(\mathrm{Y})$ shaped pattern (branched grooves).

Type III: Criss-cross pattern (intersected grooves).

Type IV: Reticular pattern, fence-like (reticular grooves).

Type V: All other patterns (undifferentiated grooves).

Akwa Ibom State is located in the southern part of Nigeria. It is one of the 36 states of the country, situated within the tropics and its proximity to the sea makes the state generally 


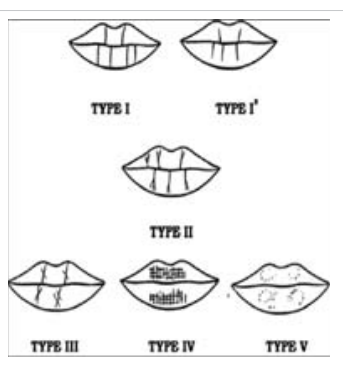

Figure 1: Pictorial representation of Suzuki and Tsuchihashi (1970) classification of lip prints.

humid. There are three major ethnic groups in Akwa Ibom State, these are: Ibibio, Annang and Oron. There are cultural similarities among these ethnic groups which can be epitomized in folklore, beliefs, dance, songs, mythology and food [7].

The specific objectives of this study are to:

a) Analyze and evaluate lip print patterns in relation to the gender from the population under study.

b) Document common lip print patterns among indigenes of Akwa Ibom State.

c) Determine sex using lip thickness and length of these indigenes.

\section{Materials and methods}

\section{Research locale}

This research work was carried out in Akwa Ibom State, among the indigenes of the state. The choice of this locale for the research is because this happens to be the hometown of the researcher and no work of this nature has been done before in Akwa Ibom State.

\section{Population size}

The study sample consisted of 50 males and 50 females who were randomly selected and recruited for the study.

\section{Sampling method}

The sampling method that was used to select the 100 subjects during the course of this work is the multi-stage stratified random sampling method. The three major ethnic groups in Akwa Ibom State formed the sampling clusters.

Stage 1: Selection of Local Government Areas using the simple random sampling method.

- The names of the 31 LGAs in AKS were written out on pieces of paper and separated into the 3 major ethnic groups where they belong.

- Three LGAs were randomly picked from the ethnic group with the largest number of LGAs while two each were picked from the remaining ethnic groups. These seven selected LGAs constituted the sampling units.
Stage 2: Selection of villages using the simple random sampling method.

- Three villages were randomly picked from each of the seven LGAs. This gave a total of 21 villages.

Stage 3: Selection of houses using the systematic sampling method.

- From each of these 21 villages, at least 5 houses were selected using a systematic random sampling technique. In this stage, the first house was chosen using random sampling. Where a household had more than one individual within the required age range (18-25), those who were willing to participate and met up with the inclusive criteria underwent random selection to select just one of them. Where there was no individual within the age range in a household, the next household was chosen.

\section{Method of data collection}

The study population consisted of 100 indigenes of Akwa Ibom State. All the subjects (males $=50$, females $=50$ ) between the age group of 18 - 25 years. A letter of introduction was obtained from the Department of Anatomy, University of Calabar, Calabar, Nigeria and an ethical clearance from Akwa Ibom State Ministry of Health stating approval for the work prior to the commencement of the research with the approval number MH/PRS/99/V.V111/563. Before the collection of the data, the purpose and procedure of the research study was carefully and thoroughly explained to the subjects. Questions were welcomed and answered at any point they did not understand the purpose and procedure. Subjects with lesions on their lips and those who were not willing to participate due to being allergic to lipstick, religious and personal reasons were excluded. Those who were willing to participate in the study, and are free from any lesions on the lips with identity cards confirming Akwa Ibom State as the state of origin were recruited into the study and their lip prints were collected after obtaining their written consent and given assurance of confidentiality.

The procedure for taking the lip sample was as follows; hand gloves and face mask were worn for preventative measures, the subject's lips were properly cleaned with face wipes to remove any particles on the lips. Dark shade nonglossy lipstick was carefully and uniformly applied on the subject's lips. This lipstick was allowed to settle for a minute after application. The transparent cellophane which is slightly larger than the thickness of the lip was measured $10 \mathrm{~cm}$ with a meter rule and then cut with a pair of scissors, which was gently and uniformly applied from the right to the left side of the lips. After getting the lip prints on the cellophane tape, the tape was then removed in one swing and stuck to the white bond paper for proper viewing with the magnifying lens. Lipstick removers were given to the subjects to clean 
off the lipstick from their lips after obtaining the print. All the lip prints collected were labeled with serial numbers, gender and age of the individuals. The names of the subjects were not recorded. The lip print pattern was studied using the magnifying lens and the acceptable classification of lip print patterns [5,6]. The length and thickness of each lip was measured using a standard caliper. The thickness of the lip was measured separately for the upper and lower lips in the midline. The length of the mouth was measured from the outermost point of one end of the lip print to the other.

\section{Lip prints analysis}

The lip analysis was carried out by examining the lip print patterns of the whole lips and then by dividing the lip prints into six portions, the reason being that the center portion of the lip is more likely to be found at the scene of the crime when analyzing cigarette ends or glassware as was suggested by Sivapathsundharam, et al. 2001 [8]. The meter rule and pencil were used to divide the lip samples into six portions (Figure 2).

The six portions include:

\section{In the upper lip;}

Right upper portion

Middle upper portion

Left upper portion

\section{In the lower lip;}

Right lower portion

Middle lower portion

Left lower portion

These portions were observed for the lip print pattern [6] using a magnifying lens. Not always can one get a complete lip print from the scene of the crime, some portions of the lip can be more commonly found in the crime scene than others. As such, data referring to the lip as a whole may not help [9].

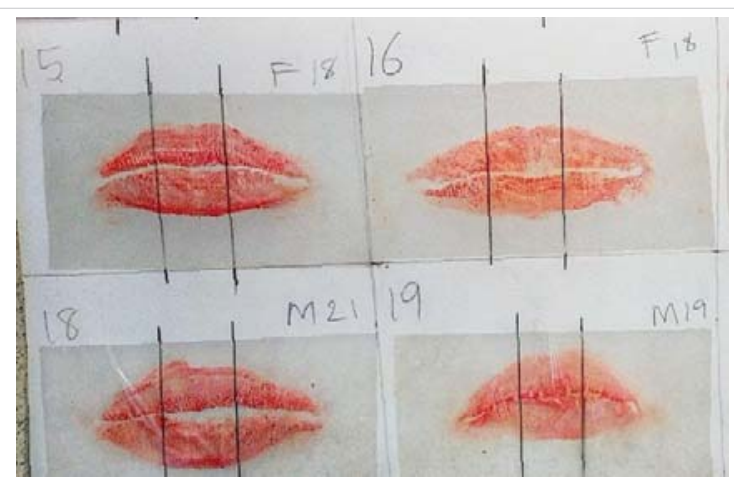

Figure 2: How the lip prints were divided into six portions for analysis.

\section{Results}

\section{Results of lip print analysis}

The statistical significance was calculated using the chisquare test for the lip print patterns while the T-test was used to calculate the thickness and length of the lips. The results of the analysis are shown Table 1.

The Table 1 shows the result of lip print patterns while considering the lip as a whole, Type I was the most prevalent in male subjects (29\%), followed by Type II (25\%), Type I' (17\%), Type IV (13\%) and Type V (9\%).

In the females, the most common lip print pattern is the Type I' (32\%), followed by Type II (18\%), and then Type I and III (14\% each), Type V (13\%) and Type V (13\%) (Table 2).

The present study, Table 2 shows the following observations:

Right Upper Portion of male subjects shows that the most common print was Type I (5.0\%), followed by Type I' $(3.7 \%)$, Type V (3.3\%), Type II (2.0\%), lastly Types III and IV (1.3\%) each. While in female subjects, the most common print was Type I' (8.0\%), followed by Type V (5.7\%), Type III $(2.0 \%)$, Type IV $(0.7 \%)$, Type I $(0.3 \%)$, then no female subject had a Type II lip print pattern $(0.0 \%)$.

Middle Upper Portion of male subjects had the most common print to be Types I and IV (4.3\%) each, Type I' (3.7\%), Types II and III (1.7\%) each and Type V was (1.0\%). In female subjects, Type I' $(5.0 \%)$ was the most common print followed by Types I and IV (4.0\%) each, Types III and V (1.7\%) each and least to be Type II $(0.3 \%)$.

Left Upper Portion of the male subjects showed Type I' $(6.7 \%)$ to be the most common print, followed by Type I (4.7\%), Type IV (2.0\%), Type V (1.7\%), Type II $(1.3 \%)$ and finally Type III $(0.3 \%)$. The most common print in the female subjects occurred as follows, Type I' (7.3\%), Type V (4.0\%), Type III (2.3\%), Type I (1.7\%), Type II (1.0\%), Type IV (0.3\%).

The occurrence in the Right Lower Portion of the male subjects is as follows: Type II (8.0\%), Type I (2.7\%), Type V (2.0\%), Types I' and IV (1.7\%) each, Type III (0.7\%) while in female subjects the prints occurred as follows: Type II (8.0\%), Type III (3.0\%), Type I' (2.7\%), Type I (1.7\%), Types IV and V $(0.7 \%)$.

Middle Lower Portion of the male subjects are as follows, Type I (9.7\%), Type II (2.7\%), Type IV (2.3\%), Type III (I.0\%), Type I' $(0.7 \%)$ and Type V $(0.3 \%)$. In female subjects, Type I'

Table 1: Distribution of lip print patterns in males and females while considering the lips as a whole.

\begin{tabular}{|c|c|c|c|c|c|c|}
\hline & Type I & Type I' & Type II & Type III & Type IV & Type V \\
\hline Males & 29 & 17 & 25 & 7 & 13 & 9 \\
\hline Females & 14 & 32 & 18 & 14 & 9 & 13 \\
\hline
\end{tabular}


Table 2: Comparison of the distribution of lip print patterns between male and female subjects in the different quadrants.

\begin{tabular}{|c|c|c|c|c|c|c|c|c|}
\hline & & Type I & 'Type I' & Type II & Type III & Type IV & Type V & Chi Sq. Test \\
\hline \multirow[t]{4}{*}{ RUP } & Male & 15 & 11 & 6 & 4 & 4 & 10 & \\
\hline & & $5.0 \%$ & $3.7 \%$ & $2.0 \%$ & $1.3 \%$ & $1.3 \%$ & $3.3 \%$ & \\
\hline & Female & 1 & 24 & 0 & 6 & 2 & 17 & \\
\hline & & $0.3 \%$ & $8.0 \%$ & $0.0 \%$ & $2.0 \%$ & $0.7 \%$ & $5.7 \%$ & $25.960^{*}$ \\
\hline \multirow[t]{4}{*}{ MUP } & Male & 13 & 11 & 5 & 5 & 13 & 3 & \\
\hline & & $4.3 \%$ & $3.7 \%$ & $1.7 \%$ & $1.7 \%$ & $4.3 \%$ & $1.0 \%$ & \\
\hline & Female & 12 & 15 & 1 & 5 & 12 & 5 & \\
\hline & & $4.0 \%$ & $5.0 \%$ & $0.3 \%$ & $1.7 \%$ & $4.0 \%$ & $1.7 \%$ & $3.862^{\mathrm{NS}}$ \\
\hline \multirow[t]{4}{*}{ LUP } & Male & 14 & 20 & 4 & 1 & 6 & 5 & \\
\hline & & $4.7 \%$ & $6.7 \%$ & $1.3 \%$ & $0 \quad .3 \%$ & $2.0 \%$ & $1.7 \%$ & \\
\hline & Female & 5 & 22 & 3 & 7 & 1 & 12 & \\
\hline & & $1.7 \%$ & $7.3 \%$ & $1.0 \%$ & $2.3 \%$ & $0.3 \%$ & $4.0 \%$ & $15.455^{\star}$ \\
\hline \multirow[t]{4}{*}{ RLP } & Male & 8 & 5 & 24 & 2 & 5 & 6 & \\
\hline & & $2.7 \%$ & $1.7 \%$ & $8.0 \%$ & $0.7 \%$ & $1.7 \%$ & $2.0 \%$ & \\
\hline & Female & 5 & 8 & 24 & 9 & 2 & 2 & \\
\hline & & $1.7 \%$ & $2.7 \%$ & $8.0 \%$ & $3.0 \%$ & $0.7 \%$ & $0.7 \%$ & $9.125^{\mathrm{NS}}$ \\
\hline \multirow[t]{4}{*}{ MLP } & Male & 29 & 2 & 8 & 3 & 7 & 1 & \\
\hline & & $9.7 \%$ & $0.7 \%$ & $2.7 \%$ & $1.0 \%$ & $2.3 \%$ & $0.3 \%$ & \\
\hline & Female & 16 & 17 & 2 & 5 & 9 & 1 & \\
\hline & & $5.3 \%$ & $5.7 \%$ & $0.7 \%$ & $1.7 \%$ & $3.0 \%$ & $0.3 \%$ & $19.948^{*}$ \\
\hline \multirow[t]{4}{*}{ LLP } & Male & 6 & 4 & 30 & 5 & 3 & 2 & \\
\hline & & $2.0 \%$ & $1.3 \%$ & $10.0 \%$ & $1.7 \%$ & $1.0 \%$ & $0.7 \%$ & \\
\hline & Female & 4 & 11 & 23 & 9 & 1 & 2 & \\
\hline & & $1.3 \%$ & $3.7 \%$ & $7.7 \%$ & $3.0 \%$ & $0.3 \%$ & $0.7 \%$ & $6.734^{\mathrm{NS}}$ \\
\hline \multirow[t]{4}{*}{ Total } & Male & 85 & 53 & 77 & 20 & 38 & 27 & \\
\hline & & $28.3 \%$ & $17.7 \%$ & $25.7 \%$ & $6.7 \%$ & $12.7 \%$ & $9.0 \%$ & \\
\hline & Female & 43 & 97 & 53 & 41 & 27 & 39 & \\
\hline & & $14.3 \%$ & $32.3 \%$ & $17.7 \%$ & $13.7 \%$ & $9.0 \%$ & $13.0 \%$ & $42.392^{*}$ \\
\hline
\end{tabular}

${ }^{*}=$ Significant at $p<0.05 ;$ NS $=$ Not Significant $(p>0.05)$

(5.7\%), Type I (5.3\%), Type IV (3.0\%), Type III (1.7\%), Type II $(0.7 \%)$ and Type $\mathrm{V}(0.3 \%)$.

Left Lower Portion of the male subjects are as follows, Type II (10.0\%), Type I (2.0\%), Type III (1.7\%), Type I' (1.3\%), Type IV (1.0\%) and Type V (0.7\%) while the female subjects are, Type II (7.7\%), Type I' (3.7\%), Type III (3.0\%), Type I (1.3\%), Type V $(0.7 \%)$ and Type IV (0.3\%).

\section{Thickness of the lips}

There was no significant difference $(p>0.05)$ in the upper lip of male and female subjects (Figure 3 ).

There was no significant difference $(p>0.05)$ in the lower lip of male and female subjects (Figures 4).

In both male and female subjects, the lower lips were significantly $(p<0.01)$ thicker than the upper lips (Figure 5).

\section{Length of the lips}

The length was significantly longer $(p>0.01)$ in males compared to females (Figures 6).

\section{Discussion}

The significance of this research is that at the end of the study the lip print pattern for Akwa Ibom indigenes would be known and documented in the lip print database for future reference and possibly used for gender determination.

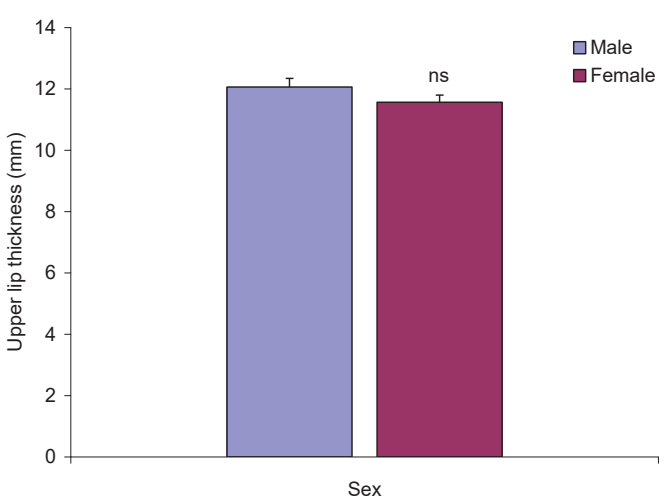

Figure 3: Comparison of upper lip thickness in male and female subjects. ns: not significant. $(p>0.05)$.

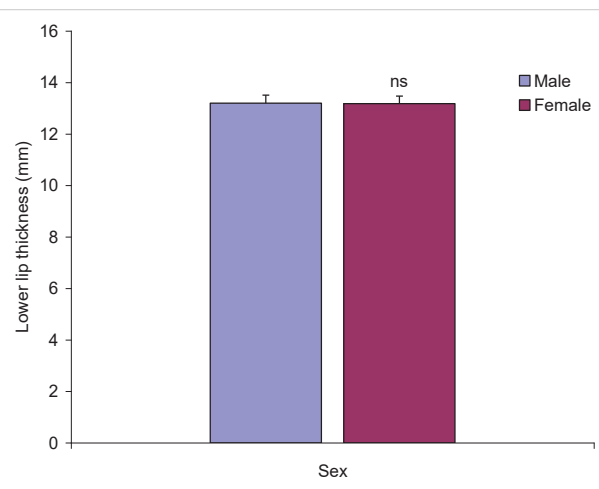

Figure 4: Comparison of Lower lip thickness in male and female subjects. ns: not significant. $(p>0.05)$. 


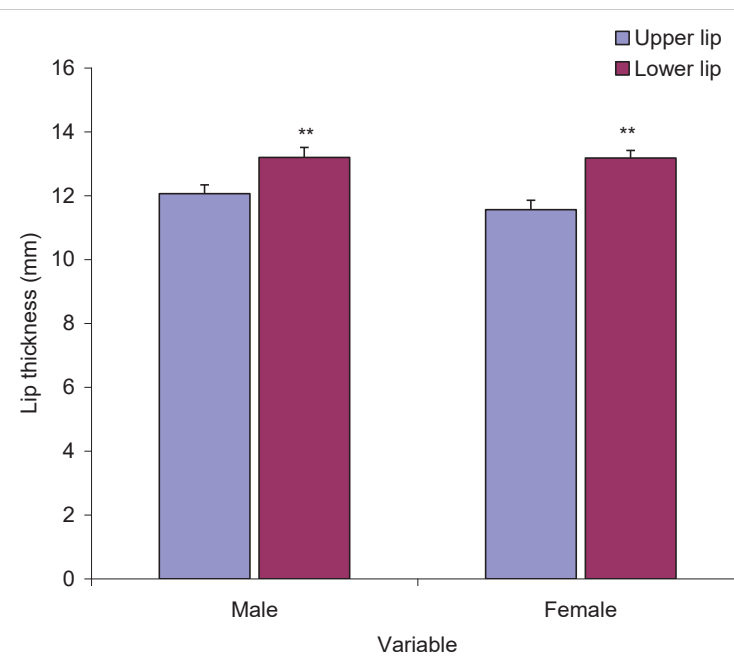

Figure 5: Comparison between upper and lower lip thickness in male and female subjects. ${ }^{* *}=$ significant at $p>0.01$.

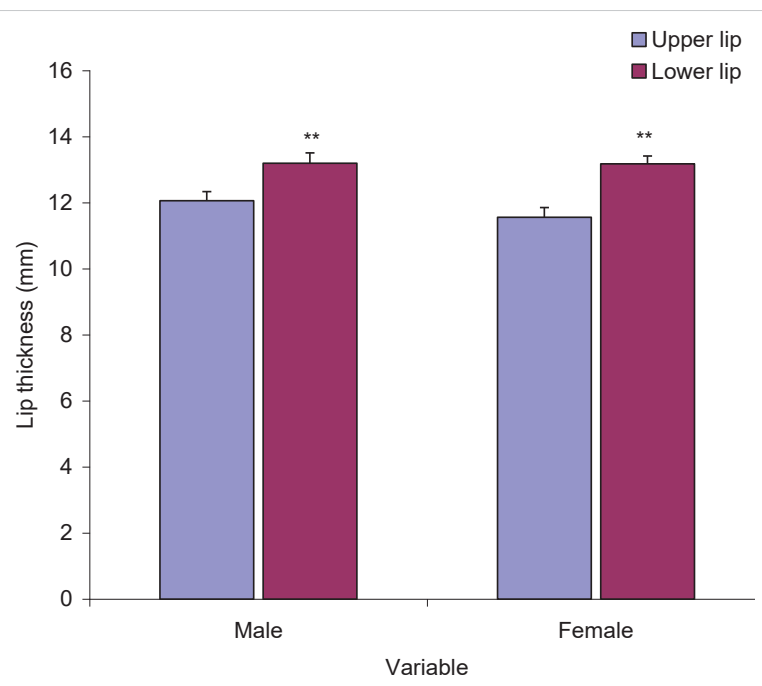

Figure 6: Comparison of lip length in male and female subjects. ${ }^{* *}=$ significant at $p>0.01$.

\section{Discussion on lip print analysis}

In the present study, lip print patterns of 100 indigenes (50 males and 50 females) of Akwa Ibom State, Nigeria were analyzed including comparing the thickness and length of both male and female subjects. Table 1 shows that while considering the lip print pattern as a whole, Type I was the most prevalent (29\%) in male subjects while that of the female subjects is the Type I'. Since the middle portion of the lip is more likely to be found on objects such as cigarettes or wine glasses at a crime scene, the middle portion of the lip has to be studied separately, hence the reasons why the lip samples were divided into six portions during analysis. Table 2 shows that the most common types of lip prints observed in male subjects while considering the lips in different portions were as follows: Right Upper Portion = Type I (5.0\%), Middle Upper Portion = Types I and IV (4.3\% each), Left Upper Portion = Type I' (6.7\%), Right Lower Portion = Type II (8.0\%), Middle Lower Portion $=$ Type I $(9.7 \%)$, Left Lower Portion $=$ Type II
(10.0\%) while in female subjects the following was observed: Type I' was the most common type of lip print in the Right, Middle, Left Upper Portions (8.0\%, 5.0\%, 6.7\% respectively), RLP = Type II (8.0\%), MLP = Type I' (5.7\%), LLP = Type II (7.7\%). Type II was never found $(0.0 \%)$ in the RUP of the lip among the female subjects. The result above (Table 2) was able to show statistical significance $(p<0.05)$ between the lip print patterns in male and female subjects in the RUP, LUP and MLP which shows that these portions of the lip can be effectively used for sex determination among indigenes of Akwa Ibom State while that of the MUP, RLP and LLP were insignificant statistically $(p>0.05)$ and they cannot be effectively used for sex determination.

Similar quadrant based studies done by Vijay, et al. [9] on 100 medical students (50 males and 50 females) in South India showed that the following was the most common lip print patterns: RUP: males = Type I', females = Type I, LUP: males $=$ Type III, females $=$ Type II, RLP: males = Type III, females = Type II, LMP = Type I in both males and females, LLP: males = Type III, females $=$ Type II. Type IV was never found in the outer portions of the lower lip among males and females. The findings showed that the outer portions of the lip can be effectively used for sex determination among medical students in South India. A study done on 200 dental students found out that Type I was the most common in the RUP and LUP among females as compared to Type I in males [10]. In the LLP and RLP Type I was most common in females as compared to Type II in males. The findings were statistically significant for sex determination.

A study on the distribution of sex differences and stability of lip print patterns in an Indian population showed that Type I and Type I' were the most and least prominent (respectively). In males Type I and in females Type III were found to be most prevalent and Type I' least seen in both sexes [11].

Lip print patterns in Rajasthani population of the Indian sub-continent results showed that most prevalent pattern in this population was found to be Type IV followed by Type I, Type V, Type III, Type I' and Type II being the least prevalent statistical analysis with chi-square test revealed no statistically significant differences were found among male and female subjects in their prevalence [12].

A study done in North India showed sexual dimorphism in the lip print patterns among different communities. Among the Brahmin males, the most common patterns found were Type II and Type III as compared to Type IV and Type I' among Brahmin females. Among the Jat community, Type III was the most common pattern found in males and females. Results of the study were statistically significant [13].

A study which was done on 600 rural and urban subjects in Maharashtra, found that Type III and Type I patterns were more common in the lateral segments of the upper lip as 
compared to Type IV in the medial segment of the upper lip. Similarly, in the lower lip Type III was more common in the lateral segment as compared to Type I in the medial segment. Type IV pattern was more common among females in the lateral segment as compared to Type I among males [14].

The study of lip print pattern in a Punjabi population revealed that in this population, no two lip prints matched with each other. Type I pattern was found to be predominant in both males and females and there was no statistically observed difference between males and females in individual lip print types [15]

A research on cheiloscopy-method of person identification and sex determination revealed Type I and Type I' to be common in females, Type IV and V were seen most commonly in males [16].

A research on the identification of sex using lip print in India, revealed that the patterns of lip prints showed significant sexual dimorphism between males and females, male lips were found to be thicker as the common lip print patterns found in males were Type III and IV while in females were Type I and Type II [1].

Vahanwala, et al. [17] in a study differentiated the sex of a person based on dominance of the lip print pattern. They suggested that presence of Type I and Type I' or Type I and Type II as the dominant patterns in the lip suggested that the lip prints belonged to females while presence of Type III, Type $\mathrm{V}$ varied patterns as the dominant types suggested that the prints belonged to males.

In a study carried out by Malik, et al. [18] which was done on 100 subjects revealed that Type I and Type I' were the most dominant types of patterns in females. Type IV and Type $V$ patterns were the dominant patterns in males.

\section{Discussion on thickness of the lip}

As seen in the result above (Figures 3,4), there was no significant difference $(p>0.05)$ in the thickness of lips between the male and female subjects, but the lower lip was significantly thicker than the upper lip $(p<0.01)$ in both subjects (Figure 6). In males, the average thickness of the upper lip was $12.1 \mathrm{~mm}$ while in females it was $11.6 \mathrm{~mm}$, the difference in the average thickness of the upper lip between male and female subjects was $0.5 \mathrm{~mm}$. This is statistically insignificant $(p>0.05)$ for sex determination. The average thickness of the lower lip in males was $13.2 \mathrm{~mm}$ while in females was 13.18 $\mathrm{mm}$ and the difference in the average thickness of the lower lip between male and female subjects was $0.02 \mathrm{~mm}$. This is also statistically insignificant ( $p>0.05)$ for sex determination. The observed thickness in the lower lip among the indigenes of Akwa Ibom State may be hereditary in nature. A study at (www.biology.online.org) revealed that blacks (Africans) generally tend to have thicker lips than whites. It can be as a result of richer and voluptuous muscles on the lower lips than the upper lips. This study site (www.biology.online.org) has also proven that larger/thicker lips create larger surface area for heat dispersion thus the anatomy of the bodies of people from relatively warm places is more inclined towards the facilitation of heat dispersion as blood passes through the vessels in the lips it is cooled before recirculating through the rest of the body [19]. As early stated, Akwa Ibom State is one of the states with a high climatic temperature, this can be the reason the lip anatomy (thicker lower lips) of the indigenes has adapted to aid in heat dispersion thus confirming the observations by Luis [19].

Contrary to research by Vijay et al (2013) [9], the lips of the male subjects (both upper and lower) were significantly thicker than that of the female subjects among South Indians. The same result was observed in a research carried out in Pradesh, India [1].

The study on upper and lower lip soft tissue thickness differs in relation to age and sex showed that the lips of males were thicker than those of females [20].

\section{Discussion on length of the lip}

Figure 6 showed that the length of lips in males was significantly longer than that of females $(p<0.01)$. The average length of the lip in males was $73.86 \mathrm{~mm}$ while in females was $68.56 \mathrm{~mm}$; the difference in the average length of the lips between males and females was $5.3 \mathrm{~mm}$. This is statistically significant $(p<0.01)$ for sex determination. There is no scientific explanation for this observation. This result is in agreements with a work done by Emelike, et al. [21] which also showed that the length of lips in males were higher than those of females among Igbo residents in Maduguri, Nigeria. While contrary to a research by Vijay, et al. [9] in which there was no significant difference in the length of lips of male and female subjects among South Indians.

A research on the eight components of a balanced smile revealed that the average lip length at rest is about $23 \mathrm{~mm}$ in males and $20 \mathrm{~mm}$ in females [22].

\section{Conclusion}

The study concluded that Type I (29\%) is the most prevalent lip print pattern in male subjects while Type I' is the most prevalent in female subjects when the lip samples are analyzed as a whole. When the lip samples are divided into six portions the RUP (25.960), LUP (15.455) and MLP (19.948) can be used to significantly determine sex among the indigenes of Akwa Ibom State and the lip length (difference of $5.3 \mathrm{~mm}$ ) is another means of sex determination since the males have a significant longer lip than the females.

\section{Recommendation}

Similar researches are recommended perhaps with a larger sample size in order to suggest more on the accuracy of identification using lip print among these indigenes. 


\section{References}

1. Sharma V, Ingle N, Kaur N, Yadav P. Identification of sex using lip prints: A clinical study. J Int Soc Prev Community Dent. 2014; 50: 173-177. PubMed: https://pubmed.ncbi.nlm.nih.gov/25625075/

2. Bharathi S, Thenmozhi M. Cheiloscopy - Lip print: A determination of sex and individual. J Pharmaceuti Sci Res. 2015; 1: 113-119.

3. Singh J, Gupta K, Sardana V, Balappanavar A, Malhotra G. Sex determination using cheiloscopy and mandibular canine index as a tool in forensic dentistry. J Forensic Den Sci. 2012; 4: 70-112.

PubMed: https://pubmed.ncbi.nlm.nih.gov/23741145/

4. Satyanarayana NK, Ajay PR. Forensic odontology cheiloscopy. Hong Kong Dent J. 2011; 91: 25-28.

5. Tsuchichashi $Y$. Studies on personal identification by means of lip prints. Forensic Sci. 1974; 3: 233-248.

PubMed: https://pubmed.ncbi.nlm.nih.gov/4858319/

6. Suzuki K, Tsuchihashi Y. New attempt of personal identification by means of lip print. J Indian Dent Assoc. 1970; 4: 8-9.

PubMed: https://pubmed.ncbi.nlm.nih.gov/5269498/

7. Akwa lbom State. Land of Promise. 2016. https://www.cometonigeria.com

8. Sivapathasundharam B, Ajay P, Sivakumar G. Lip prints (Cheiloscopy). Indian J Dent Res. 2001; 12: 234-457.

PubMed: https://pubmed.ncbi.nlm.nih.gov/11987663/

9. Vijay K, Pravir B, Naveen R. Efficacy of cheiloscopy in determination of sex among South Indians. J Clin Diagnostic Res. 2013; 7: 2193-219. PubMed: https://pubmed.ncbi.nlm.nih.gov/24298473/

10. Amith $\mathrm{H}$, Anil V, Nagesh L. Lip prints - Can it add in individual identification. J Oral Health Commun Dentis. 2011; 5: 113-118.

11. Kapoor N, Tiwari P. Study of lip prints among the population of Marathi Community. Int J Sci Res Publication. 2013; 45: 1-8.

12. Sharma R, Sharma K, Preethi N, Degra H, Rajmani H. Cheiloscopy: A study of morphological patterns of lip prints in Rajasthani population. $J$ Res Med Dent Sci. 2015; 3: 35-38.

13. Vats $Y$, Dhall J, Kapoor A. Gender variation in morphology patterns of lip prints among some North Indian population. J Forensic Dent Sci. 2012; 4: 19-23.

PubMed: https://www.ncbi.nlm.nih.gov/pmc/articles/PMC3470412/

14. Augustine J, Barpande S, Tupkari J. Cheiloscopy as an adjunct to forensic identification: A study of 600 individuals. J Forensic Odontostomatol. 2008; 27: 44-52.

PubMed: https://pubmed.ncbi.nlm.nih.gov/22717789/

15. Sandhu S, Bansal H, Monga $P$, Bhandari R. Study of lip print pattern in a Punjabi Population. J Forensic Dent Sci. 2012; 4: 24-28.

PubMed: https://pubmed.ncbi.nlm.nih.gov/23087578/

16. Dongarwar G, Bhowate R, Degwekar S. Cheiloscopy - Method of person identification and sex determination. Sci Rep. 2013; 612: 10.4172 .

17. Vahanwalla S, Nayak C, Pagare S. Study of lip prints as an aid to sex determination. Medico-legal update. 2005; 5: 93-98.

18. Malik R, Goel S. Cheiloscopy - A deterministic aid for forensic sex determination. J Indian Academy Oral Med Radiol. 2011; 23: 17-19.

19. Luis. Why do Africans have large noses and lips? 2009. https://forum. biologyonline.com/topic/why-do-africans-have-large-noses-and-lips

20. Bozdag Z, Kurkcuoglu A, Ustdal A, Cam Y, Ozkan O. Upper and lower lip soft tissue thicknesses differ in relation to age and sex. Int $\mathrm{J}$ Morphol. 2017; 35: 852-858.

21. Emenike NV, Garba SH, Dalori BM, Numan Al. Anthropometric Study of Lip-Nose Complex in adult Igbo's resident in Maiduguri. J Dental Med Sci. 2012; 1: 29-31.

22. Sabri R. The eight components of a balanced smile. J Clin Orthod. 2005; 34: 155-157.

PubMed: https://pubmed.ncbi.nlm.nih.gov/15888949/ 